$$
T R / N / 20
$$

NASA/CR-2002-211872

\section{Ferroelectric Emission Cathodes for Low-Power Electric Propulsion}

Scott D. Kovaleski

QSS Group, Inc., Cleveland, Ohio
2002137609

607193

AIAA-2002-4242

$16 \mathrm{Pg}_{5}$ 
Since its founding, NASA has been dedicated to the advancement of aeronautics and space science. The NASA Scientific and Technical Information (STI) Program Office plays a key part in helping NASA maintain this important role.

The NASA STI Program Office is operated by Langley Research Center, the Lead Center for NASA's scientific and technical information. The NASA STI Program Office provides access to the NASA STI Database, the largest collection of aeronautical and space science STI in the world. The Program Office is also NASA's institutional mechanism for disseminating the results of its research and development activities. These results are published by NASA in the NASA STI Report Series, which includes the following report types:

- TECHNICAL PUBLICATION. Reports of completed research or a major significant phase of research that present the results of NASA programs and include extensive data or theoretical analysis. Includes compilations of significant scientific and technical data and information deemed to be of continuing reference value. NASA's counterpart of peerreviewed formal professional papers but has less stringent limitations on manuscript length and extent of graphic presentations.

- TECHNICAL MEMORANDUM. Scientific and technical findings that are preliminary or of specialized interest, e.g., quick release reports, working papers, and bibliographies that contain minimal annotation. Does not contain extensive analysis.

- CONTRACTOR REPORT. Scientific and technical findings by NASA-sponsored contractors and grantees.
- CONFERENCE PUBLICATION. Collected papers from scientific and technical conferences, symposia, seminars, or other meetings sponsored or cosponsored by NASA.

- SPECIAL PUBLICATION. Scientific, technical, or historical information from NASA programs, projects, and missions, often concerned with subjects having substantial public interest.

- TECHNICAL TRANSLATION. Englishlanguage translations of foreign scientific and technical material pertinent to NASA's mission.

Specialized services that complement the STI Program Office's diverse offerings include creating custom thesauri, building customized databases, organizing and publishing research results ... even providing videos.

For more information about the NASA STI Program Office, see the following:

- Access the NASA STI Program Home Page at http://www.sti.nasa.gov

- E-mail your question via the Internet to help@sti.nasa.gov

- Fax your question to the NASA Access Help Desk at 301-621-0134

- Telephone the NASA Access Help Desk at 301-621-0390

- Write to:

NASA Access Help Desk

NASA Center for AeroSpace Information 7121 Standard Drive Hanover, MD 21076 


\section{Ferroelectric Emission Cathodes for Low-Power Electric Propulsion}

Scott D. Kovaleski

QSS Group, Inc., Cleveland, Ohio

Prepared for the

38th Joint Propulsion Conference and Exhibit cosponsored by AIAA, ASME, SAE, and ASEE

Indianapolis, Indiana, July 7-10, 2002

Prepared under Contract NAS3-00145

National Aeronautics and

Space Administration

Glenn Research Center 
This report contains preliminary findings, subject to revision as analysis proceeds.

Available from

NASA Center for Aerospace Information 7121 Standard Drive

Hanover, MD 21076
National Technical Information Service 5285 Port Royal Road Springfield, VA 22100 


\title{
FERROELECTRIC EMISSION CATHODES FOR LOW-POWER ELECTRIC PROPULSION
}

\author{
Scott D. Kovaleski \\ QSS Group, Inc. \\ Cleveland, Ohio 44135
}

\begin{abstract}
$\underline{\text { Abstract }}$
Low- or no- flow electron emitters are required for lowpower electric thrusters, spacecraft plasma contactors, and electrodynamic tether systems to reduce or eliminate the need for propellant/expellant. Expellantless neutralizers can improve the viability of very lowpower colloid thrusters, field emission electric propulsion devices, ion engines, Hall thrusters, and gridded vacuum arc thrusters. The NASA Glenn Research Center (GRC) is evaluating ferroelectric emission (FEE) cathodes as zero expellant flow rate cathode sources for the applications listed above. At GRC, low voltage ( 100 s to $\sim 1500 \mathrm{~V}$ ) operation of FEE cathodes is examined. Initial experiments, with unipolar, bipolar and RF burst applied voltage, have produced current pulses 250 to $1000 \mathrm{~ns}$ in duration with peak currents of up to $2 \mathrm{~A}$ at voltages at or below $1500 \mathrm{~V}$. In particular, FEE cathodes driven by RF burst voltages from 1400 to $2000 \mathrm{~V}$ peak to peak, at burst frequencies from 70 to $400 \mathrm{kHz}$, emitted average current densities from 0.1 to $0.7 \mathrm{~A} / \mathrm{cm}^{2}$. Pulse repeatability as a function of input voltage has been initially established. Reliable emission has been achieved in air background at pressures as high as $10^{-6}$ Torr.
\end{abstract}

\section{Introduction}

A propellantless neutralizer eliminates the need for the propellant of a low power electric propulsion (EP) thruster to be diverted through the neutralizer. In some cases, a complex expellant storage and feed system can be eliminated. Electric propulsion thrusters operating up to $100 \mathrm{~W}$, like colloid thrusters, field emission electric propulsion thrusters, and small ion thrusters and Hall thrusters would benefit from the development of propellantless neutralizers. These neutralizers must be capable of stable current emission for the life of the EP device, in a potentially oxidizing and sputtering environment.

There is a growing need for low thrust propulsion, for micro-spacecraft and for attitude adjustment of larger spacecraft, that is driving research into propellantless cathodes for EP. The current state-of-the-art neutralizer cathode for electric propulsion is the hollow cathode, which has substantial propellant requirements for efficient, low power operation [1]. The oldest EP neutralizer is the hot tungsten filament, which is propellantless, but suffers from an unacceptably short lifespan in EP relevant conditions [2]. Field emission array (FEA) cathodes are being widely studied to fill the gap of propellantless neutralization. Unfortunately, FEA life is limited when exposed to background gas pressures above $10^{-8}$ Torr due to sputtering and surface chemistry $[3,4]$. An alternative propellantless cathode technology that is capable of providing high emission currents in appreciable gas backgrounds is the ferroelectric emission (FEE) cathode.

High current density electron emission from ferroelectric ceramics was first reported by Gundel [5]. Electron emission from ferroelectric ceramics, of 1 to $100 \mathrm{~A} / \mathrm{cm}^{2}$, is achieved when a fast high voltage pulse, usually a few $\mathrm{kV}$, is applied across a ceramic that is a few millimeters thick. The non-emitting surface of the ceramic is generally covered with a solid conducting electrode, and the emitting surface is partially covered by a conducting grid. FEE cathodes have been driven by unipolar [5] or bipolar [6] applied pulses. The postulated mechanisms for FEE include fast polarization reversal [6], triple point emission [7], and surface plasma extraction [8]. FEE cathodes have been examined as cathodes for traveling wave tubes [9], gas spark switches, flat panel displays [10], and discharge lamps [11]. FEE cathodes have been operated in vacuum conditions ranging from $10^{-7}$ Torr to 0.1 Torr.

At the NASA Glenn Research Center, ferroelectric cathodes are currently being studied for use as electric propulsion thruster neutralizers. These cathodes are being operated under a variety of conditions such as unipolar, bipolar, and RF burst driven, with and without extraction voltages. The cathodes are generally being operated with drive voltages at or near the emission threshold for ferroelectric emission. This paper summarizes these initial experiments and brings forth RF driven FEE cathodes for the first time. The results of these experiments show that RF driven ferroelectric emission cathodes hold great promise as a propellantless cathode for electric propulsion applications. 


\section{Experimental Apparatus}

Schematics of the ferroelectric cathode apparatuses used for these experiments are shown in Figure 1. Two types of lead zirconate titanate (PZT) ferroelectric ceramics, APC-856 and APC-880, were tested [12]. The ceramics were $1 \mathrm{~mm}$ thick and $2 \mathrm{~cm}$ in diameter, with a solid conducting electrode on the non-emitting side. The emitting surface area was often masked down, yielding emission areas between 0.16 and $3.1 \mathrm{~cm}^{2}$. Various grids were employed on the emitting side, including Mo screen, Ag paint, and Mo thin films. The anode to cathode gap for these experiments was typically 1 to $3 \mathrm{~mm}$. Both screen and solid anodes were used. The anodes were insulated from the cathode by polyimide and mica isolators. These grid types, diode geometries, and cathode operating conditions are summarized in Table 1.

Ferroelectric cathodes require a high voltage pulse for operation. Positive-going and negative-going unipolar pulses, as well as bipolar and RF bursts, were delivered to the non-emitting rear electrode by a high voltage pulser. The pulser can deliver a 0 to $2000 \mathrm{~V}$ positive or negative going pulse with pulse width as short as $18 \mu \mathrm{s}$ and rise times as short as $400 \mathrm{~ns}$. For the $1 \mathrm{~mm}$ thick ceramics used in these experiments, the electric field applied across the ceramic could reach values as high as $2 \times 10^{6} \mathrm{~V} / \mathrm{m}$. Typical unipolar pulses are shown in Figure 2. The APC-856 ceramic with pressed-on or painted-on emitting surface grids was typically driven by unipolar pulses. For bipolar pulse and RF burst operation, the pulser was used to excite a resonant circuit. For bipolar pulse operation, the resonant circuit was excited with a single unipolar high voltage pulse. For RF burst operation, a burst of 2 to 7 unipolar pulses at the resonant frequency excited the LC resonant circuit. Figure 3 shows examples of the bipolar and RF burst pulses used in these experiments. The RF burst and bipolar pulse driven cathodes were either APC-856 or APC-880. These cathodes had striped grids on the emitting surface consisting of $100 \mathrm{~nm}$ thick thin films of Mo. A foil provided electrical contact to the grids. The grid on the emitting surface of the ceramic was typically grounded for unipolar, bipolar, and RF burst driven experiments. For some bipolar pulse driven experiments, however, pulses were applied to the emitting surface grid with the rear electrode grounded. For the unipolar pulse driven experiments, the anode was biased a few 10 s of volts positive of ground. For the RF burst experiments, the anode was shunted to ground through a $22 \Omega$ current-viewing resistor. Electrical schematics for the FEE experiments are also shown in Figure 1.

\section{Results and Discussion}

Unipolar pulsed, bipolar pulsed and RF burst high voltage drove the ferroelectric emission in these cathode experiments. Unipolar driven electron emission was achieved at threshold voltages of $\sim-800 \mathrm{~V}$ and $\sim 600 \mathrm{~V}$. Unfortunately, substantial damage to the cathode surface was sustained. Bipolar pulses also successfully stimulated electron emission from PZT. RF burst driven cathodes showed the most promising results, emitting average currents on the order of 0.1 to $1 \mathrm{~A} / \mathrm{cm}^{2}$ at applied RF voltages from 1400 to $2000 \mathrm{~V}$ peak to peak. The experiments presented here and their critical results are summarized in Table 1.

\section{Unipolar and Bipolar Pulsed Operation}

Initial cathode experiments were conducted with unipolar driving pulses. Current emission was successfully achieved with both positive and negative going unipolar pulses applied to the non-emitting electrode. Figure 4 shows the electron emission reliability under unipolar pulse drive. Defining the applied voltage threshold for ferroelectric emission as the voltage at which $>80 \%$ of the applied pulses result in current transport detected at the anode, we can find the threshold for emission from Figure 4. For a cathode with a Mo mesh emitting surface electrode and negative applied pulses, the emission threshold was about $800 \mathrm{~V}$. For a cathode with Ag paint emitting surface electrodes, the negative applied pulse threshold was approximately $-900 \mathrm{~V}$ and the positive pulse threshold was about $600 \mathrm{~V}$. It would appear from this data that positive applied pulses have a lower emission threshold, though only two cathodes were tested. A larger sample would be required to make a definitive statement about polarity and emission threshold.

The peak emission currents measured with unipolar pulse driven cathodes are given in Table 1. The current values are given for applied voltages above the emission threshold. The values represent the peak transported current measured at the anode, averaged over 128 applied unipolar pulses. The negative polarity pulses resulted in peak currents near $300 \mathrm{~mA}$ and current densities of about $100 \mathrm{~mA} / \mathrm{cm}^{2}$, whereas positive polarity pulses yielded an order of magnitude less current with a peak current of $14 \mathrm{~mA}$, and a peak current density of $5 \mathrm{~mA} / \mathrm{cm}^{2}$. In all cases, the current pulse widths were about $1 \mu \mathrm{s}$.

The major drawback to unipolar pulse operation of ferroelectric cathodes is damaged induced on the cathode surface. Figure 5 shows an APC-856 PZT ceramic that had Mo screen grids and was operated in 
unipolar pulse mode. Damage on the cathode surface is marked by the darkening of the cathode surface. Under magnification, deposits of metallic material, probably originating from the grids, can be seen on surface of the ceramic. Ferroelectric cathodes are known to produce plasmas over the ceramic surface [8]. Under the influence of unipolar driving pulses, this surface plasma likely results in fairly extensive erosion of the metallic grids on the cathode emitting surface. One test was run to look at long term current emission stability under negative unipolar driving pulses. The cathode emitted current for only about 5000 applied pulses. The cathode was observed to be heavily damaged upon post-test inspection, which led to the conclusion that the damage had terminated cathode operation.

Bipolar driven FEE cathode operation was also attempted. The experiment details are given in Table 1. Current emission was achieved, with peak emission current of up to $2 \mathrm{~A}$. Pulse reliability was not very good except at high applied voltage; at best only about $80 \%$ of the applied pulses at $1000 \mathrm{~V}$ peak voltage resulted in current transport. In one case, $100 \%$ transport was achieved, but for peak applied voltage of $1400 \mathrm{~V}$. Two important things were observed for bipolar pulse driven operation, however. Electron emission occurred when the electric field vector across the ceramic pointed away from the diode gap, and very little cathode surface damage was observed, especially when the driving pulses were applied to the rear electrode.

\section{$\underline{\text { RF Burst Driven Operation }}$}

Given the modest and mixed success with bipolar pulse driven FEE cathodes, RF burst driven operation was attempted, to simulate cathodes driven by CW RF power. This method of cathode drive is desirable since the cathode can be operated in a continuously pulsed mode for neutralization of a DC electric propulsion thruster beam.

With a few cycles of RF driving voltage applied to a ferroelectric ceramic with thin film grids, current emission could be easily and repeatedly produced. Figure 6 shows the average electron current emitted and the net charge emitted per cycle. The average current is defined as the average current emitted per cycle for the 7 cycle bursts. Average current magnitudes were between 4 and $300 \mathrm{~mA}$, and average current densities ranged from 10 to $700 \mathrm{~mA} / \mathrm{cm}^{2}$, depending on driving frequency and ceramic material. For APC-880, typical peak emission currents were about $600 \mathrm{~mA}$, and for APC-856 the peak emission current was as high as
$1.5 \mathrm{~A}$. One notable trend is that while the net charge per pulse generally decreases as frequency increases, the average emitted current increases. This trend can be explained by the observation that the current pulse width does not increase much at low frequencies. So at higher frequency, the duty cycle for current emission is much higher.

The electron emission as a function of applied driving voltage for RF burst driven operation is shown in Figure 7. The emission threshold for an APC-856 PZT cathode was about $700 \mathrm{~V}$ and the threshold for APC880 was about $1100 \mathrm{~V}$. Obviously, a significant dependence of emission threshold on material was observed. Recall from the previous paragraph and Table 1 that APC-856 also emits about twice as much current as APC-880. The reason for these material dependences is not understood. Note also that no dependence on applied RF driving frequency was observed.

Figure 8 plots the current-voltage characteristic within an RF cycle for RF burst driven APC-880 ceramics. The emitted electron current through an RF cycle is plotted as a function of the voltage applied across the ceramic. The peak emission current occurs at instantaneous voltage values from $-800 \mathrm{~V}$ to $-1200 \mathrm{~V}$ applied to the rear electrode, moving to higher values with higher frequencies. The characteristic also becomes more peaked at the voltage corresponding to maximum current emission with increasing frequency. Careful observation near zero and positive applied voltages reveals a slight positive current (negative electron current). This slight current is real and well above any displacement current in the circuit. This could be ion current to the anode, which would confirm plasma production, or electron current back toward the ceramic surface.

Additionally, RF driven FEE cathodes appear to perform well in background gases. Figure 9 plots the emission current density versus background gas pressure of field emitter arrays and ferroelectric emitters. It should be noted that the comparison in Figure 9 is not strictly valid, since the field emitters were operated DC for more than an hour in the gas background, as compared the FEE cathodes which were operated at duty cycles of $10^{-5}$ to $10^{-4}$ for 1000 to 2000 bursts over a period of a few hours. However, Figure 9 does hold some indication that FEE cathodes will perform well in electric propulsion relevant gas backgrounds, and that FEE cathodes are capable of providing current densities similar to FEAs. 


\section{$\underline{\text { Conclusions }}$}

Electron emission has been successfully achieved from ferroelectric PZT ceramics. With unipolar driving pulses of a few hundred volts, electron current densities up to $100 \mathrm{~mA} / \mathrm{cm}^{2}$ could be extracted. Unfortunately, the cathodes were severely damaged after a relatively small number of applied pulses. A plasma formed over the surface of the ceramic is likely to be the cause of the cathode damage. Bipolar driving pulses also produced electron emission, up to $7 \mathrm{~A} / \mathrm{cm}^{2}$ peak current density, with little observed damage to the ceramic or emitting surface grids. The emission was largely unrepeatable and required higher peak applied voltages than unipolar mode. RF burst driven cathodes were shown to reliably emit from 10 to $700 \mathrm{~mA} / \mathrm{cm}^{2}$ average current density, depending on material, and at relatively low peak voltage.

The RF burst driven ferroelectric emission cathodes indicate a great deal of promise for development of $\mathrm{CW}$ RF driven FEE cathodes for electric propulsion. A CW cathode will be required to neutralize a DC electric propulsion thruster beam, and that cathode must be capable of reliably and continuously producing current. RF burst drive of FEE cathodes has been shown to be very reliable. Also, a FEE cathode driven by a CW RF power supply is conceivable.

\section{$\underline{\text { References }}$}

1. Patterson, M.J., Oleson, S.R., "Low-power ion propulsion for small spacecraft," AIAA Paper No. 973060, Proceedings of the $33^{\text {rd }}$ AIAA/ASME/SAE/ASEE Joint Propulsion Conference, Seattle, WA, July 6-9, 1997.

2. Kaufman, H.R., "Technology of electron bombardment ion thrusters," Advances in Electronics and Electron Physics, vol. 36, New York: Academic Press, Inc., 1974.

3. Chalamala, B.R., Wallace, R.M., Gnade, B.E., "Effect of $\mathrm{O}_{2}$ on the electron emission characteristics of active molybdenum field emission cathode arrays," $J$. Vac. Sci. Technol. B 16, 2859-2865, September 1998.

4. Marrese-Reading, C., Polk, J., "Experimental performance evaluations of Mo and ZrC-coated Mo field emission array cathodes in oxygen environments," IEPC Paper No. 01-278, Proceedings of the $27^{\text {th }}$ International Electric Propulsion Conference, Pasadena, CA, 15-19 October, 2001.
5. Gundel, H., Riege, H., Wilson, E.J.N., Handerek, J., Zioutas, K., "Fast polarization changes in ferroelectrics and their application in accelerators," Nucl. Instrum. Methods Phys. Res. A 280, 1-6, August 1989.

6. Rosenman, G., Shur, D., Garb, Kh., Cohen, R., Krasik, Ya. E., "Polarization switching in ferroelectric cathodes," J. Appl. Phys. 82, 772-778, July 1997.

7. Puchkarev, V.F., Mesyats, G.A., "On the mechanism of emission from the ferroelectric ceramic cathode," J. Appl. Phys. 78, 5633-5637, November 1995.

8. Dunaevsky, A., Krasik, Ya.E., Felsteiner, J., Dorfman, S., "Electron/ion emission from the plasma formed on the surface of ferroelectrics. I. Studies of plasma parameters without applying an extracting voltage," J. Appl. Phys. 85, 8464-8473, June 1999.

9. Rosenman, G., Shur, D., Krasik, Ya.E., Dunaevsky, A., "Electron emission from ferroelectrics," J. Appl. Phys. 88, 6109-6161, December 2000.

10. Auciello, O.H., McGuire, G.E., "Thin film ferroelectric flat panel display devices, and methods for operating and fabricating same," U.S. Patent No. 5453661, September, 1995.

11. Vollkommer, F., Hitzschke, L., "Method of operating a discharge lamp with a cold cathode structure having ferroelectric between," U.S. Patent No. 6157145, December, 2000.

12. American Piezo Ceramics, Inc., "Piezo ceramics, piezo crystals, ultrasonic transducers, piezo sensors, single crystals, alum," http://www.americanpiezo.com/, Accessed March 8, 2001. 
Table 1. Summary of ferroelectric emission cathode experiments and significant results.

\begin{tabular}{|c|c|c|c|c|c|c|c|c|c|c|c|}
\hline $\begin{array}{c}\text { Facility } \\
\text { Press. } \\
\left(10^{-7}\right. \\
\text { Torr }) \\
\end{array}$ & $\begin{array}{l}\text { Grid } \\
\text { Mat'I }\end{array}$ & $\begin{array}{l}\text { Emis. } \\
\text { Area } \\
\left(\mathrm{cm}^{2}\right)\end{array}$ & $\begin{array}{l}\text { Diode } \\
\text { Gap } \\
(\mathrm{mm})\end{array}$ & $\begin{array}{l}\text { Rear } \\
\text { Elec. } \\
\text { Pot'l }\end{array}$ & $\begin{array}{l}\text { Grid } \\
\text { Pot'l }\end{array}$ & $\begin{array}{c}\text { Anode } \\
\text { Bias }\end{array}$ & $\begin{array}{l}\text { Freq. } \\
\text { (kHz) }\end{array}$ & $\begin{array}{l}\text { No. } \\
\text { cyc. }\end{array}$ & $\begin{array}{l}\text { Thres- } \\
\text { hold } \\
\text { (V) }\end{array}$ & $\begin{array}{c}\text { Peak } \\
\text { Current } \\
\text { (A) }\end{array}$ & $\begin{array}{c}\text { Peak } \\
\text { Current } \\
\text { Density } \\
\left(\mathrm{A} / \mathrm{cm}^{2}\right) \\
\end{array}$ \\
\hline \multicolumn{12}{|c|}{ Unipolar Pulses, APC-856 Ceramic } \\
\hline 3 & $\begin{array}{c}\text { Mo } \\
\text { screen }^{1}\end{array}$ & 3.1 & 2 & $\mathrm{HVP}^{5}$ & gnd & \begin{tabular}{|c|}
$50 \mathrm{~V}$ \\
$150 \mathrm{~V}$
\end{tabular} & & & -800 & $\sim 0.250$ & 0.08 \\
\hline 5 & $\begin{array}{l}\text { Silver } \\
\text { paint }^{2}\end{array}$ & 3.1 & 2 & $\mathrm{HVP}^{5}$ & gnd & $\begin{array}{l}50 \mathrm{~V} \\
10 \mathrm{~V}\end{array}$ & & & $\begin{array}{c}600 \\
-900 \\
\end{array}$ & $\begin{array}{l}\sim 0.014 \\
\sim 0.300 \\
\end{array}$ & $\begin{array}{c}0.005 \\
0.1\end{array}$ \\
\hline \multicolumn{12}{|c|}{ Bipolar Pulses, APC-880 Ceramic } \\
\hline $4-6$ & $\begin{array}{c}\text { Mo } \\
\text { thin } \\
\text { film }^{3}\end{array}$ & $\begin{array}{c}0.16- \\
0.30\end{array}$ & $\begin{array}{c}1.13- \\
1.63\end{array}$ & $\begin{array}{l}\text { gnd or } \\
0 \text { to } 500 \\
\text { VDC }\end{array}$ & $\begin{array}{c}\text { gnd } \\
\text { or } \\
\text { HVP }^{5}\end{array}$ & $50 \mathrm{~V}$ & 250 & 1 & $\begin{array}{l}1500- \\
3000^{4}\end{array}$ & $0.4-2$ & $2-7$ \\
\hline \multicolumn{12}{|c|}{ RF Burst, APC-880 Ceramic } \\
\hline $1-10$ & $\begin{array}{l}\text { Mo } \\
\text { thin } \\
\text { film }\end{array}$ & 0.4 & 0.88 & $\mathrm{HVP}^{5}$ & gnd & gnd & $\begin{array}{c}360 \\
250 \\
180 \\
68 \\
\end{array}$ & 7 & $2000^{4}$ & 0.6 & 1.5 \\
\hline \multicolumn{12}{|c|}{ RF Burst, APC-856 Ceramic } \\
\hline 4 & $\begin{array}{l}\text { Mo } \\
\text { thin } \\
\text { film }^{3}\end{array}$ & 0.4 & 0.88 & $\mathrm{HVP}^{5}$ & gnd & gnd & $\begin{array}{l}280 \\
410\end{array}$ & 7 & $1400^{4}$ & 1.5 & 4 \\
\hline
\end{tabular}

1. Mo Screen - molybdenum, $0.38 \mathrm{~mm}$ thick, holes HCP, center spacing $2.5 \mathrm{~mm}$

2. Silver paint - silver paint stripes with a contact wire

3. Mo thin film - $1 \mathrm{~mm}$ thick stripes of molybdenum separated by $1 \mathrm{~mm}$ with a foil or wire contact

4. Bipolar and RF threshold voltages are peak to peak voltages.

5. HVP - high voltage pulse 


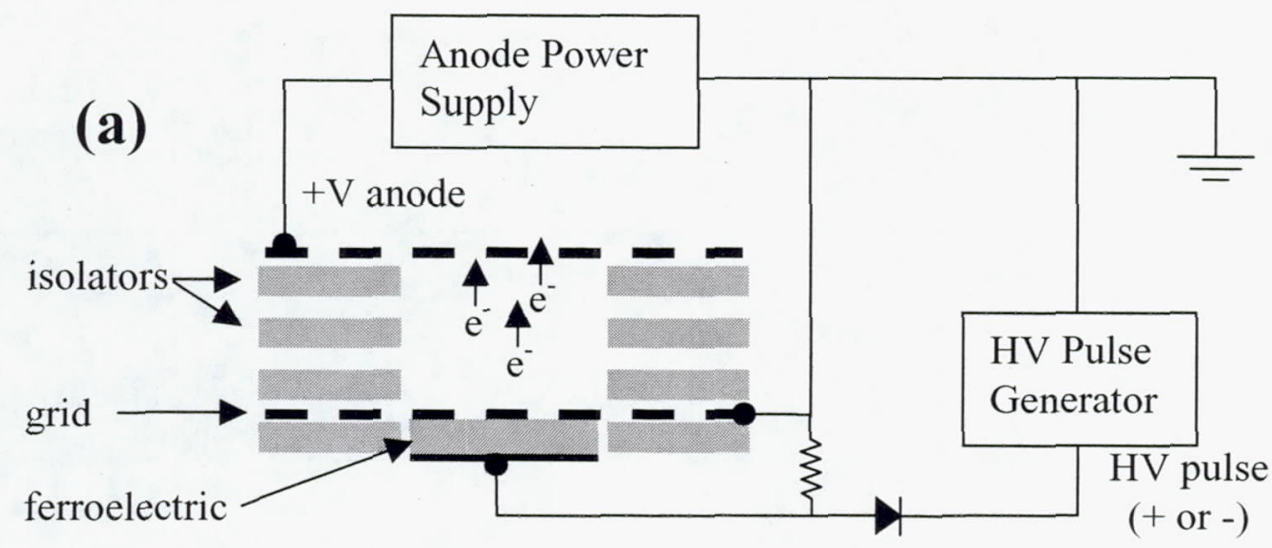

(b)

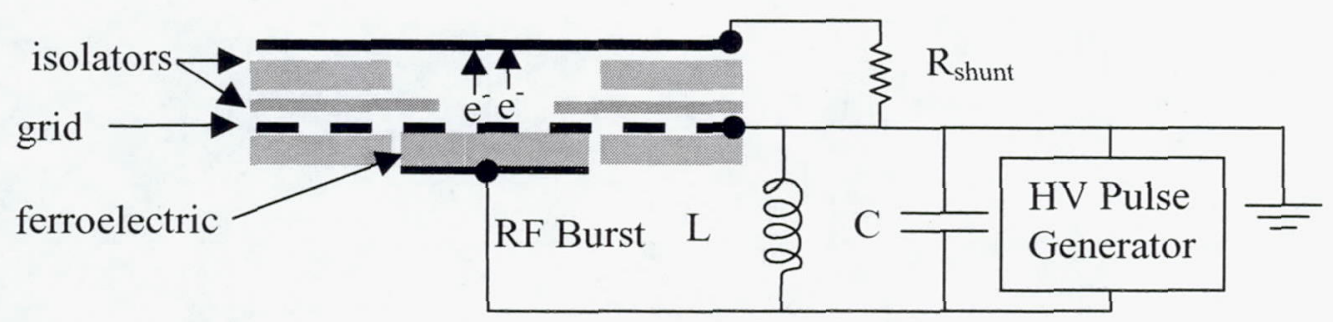

Figure 1. Schematic of the ferroelectric emission cathode assembly. Schematic (a) represents the experimental configuration for unipolar driven cathode operation, schematic (b) represents the configuration for bipolar and RF burst driven operation.

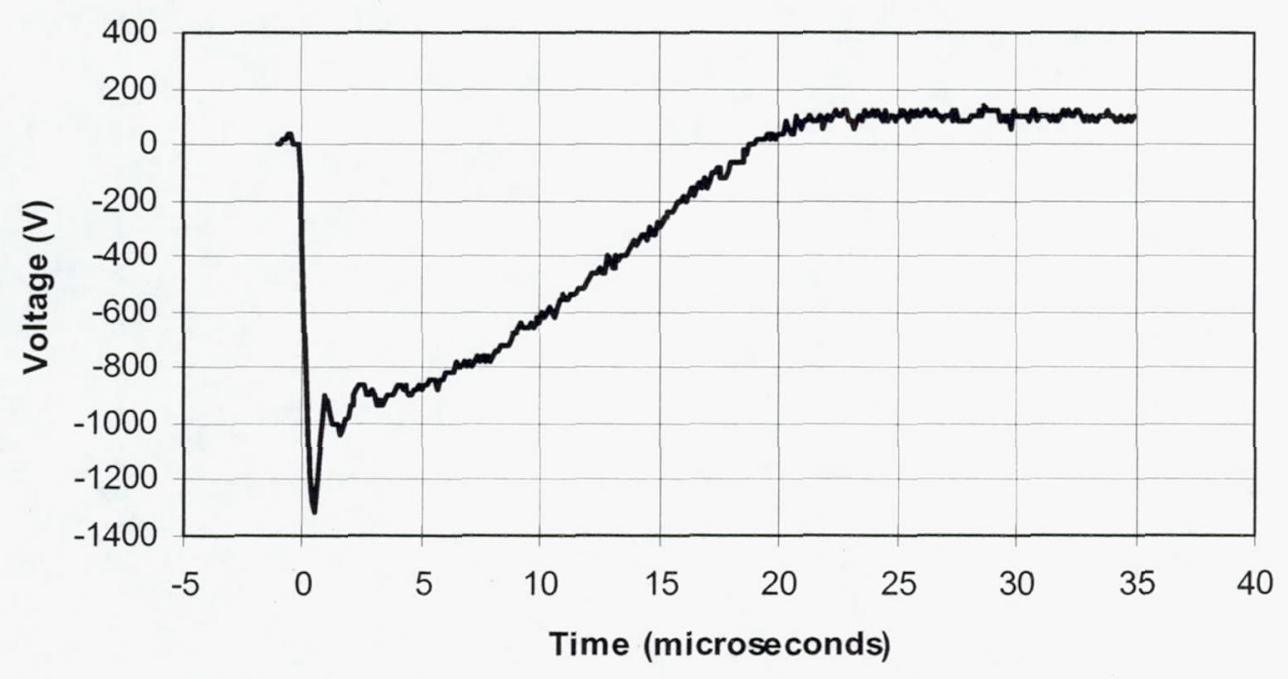

Figure 2. Typical unipolar pulse voltage waveform. 


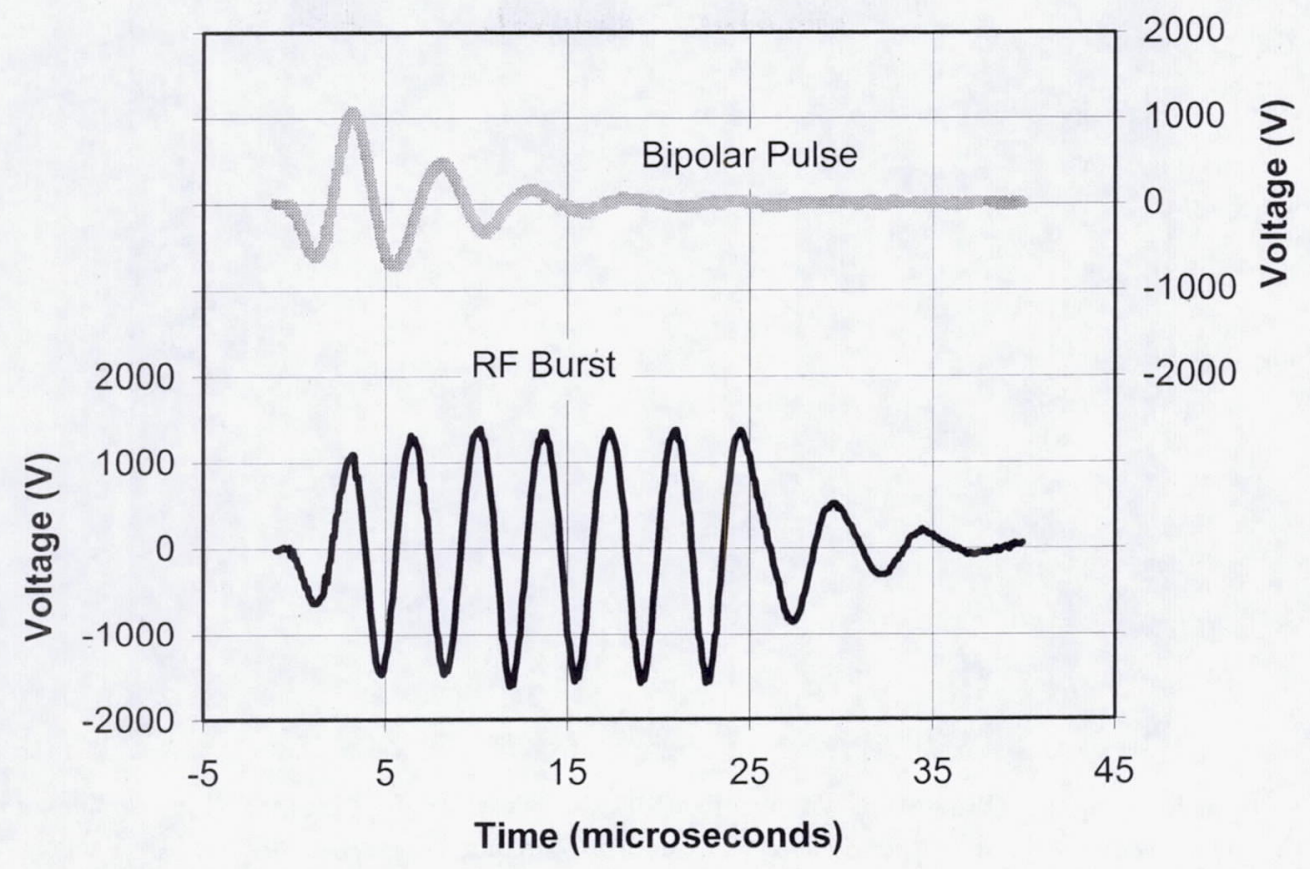

Figure 3. Typical bipolar pulse and RF burst voltage waveforms.

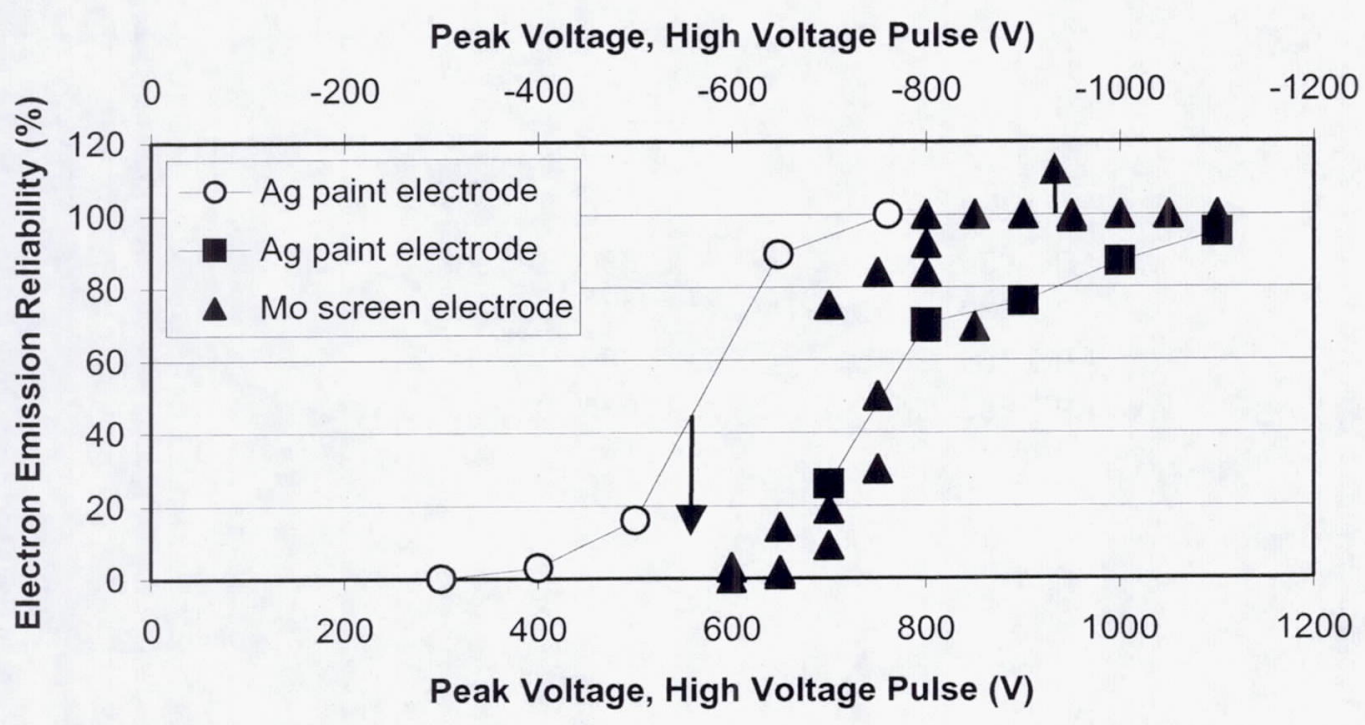

Figure 4. Electron emission reliability as a function of applied unipolar pulse voltage. The emission threshold is arbitrarily defined as the peak applied voltage above which $80 \%$ or more of the applied voltage pulses result in current transport. The open symbols are data from a cathode driven by positive going unipolar pulses; the closed symbols are data from a cathode driven by negative going unipolar pulses. 


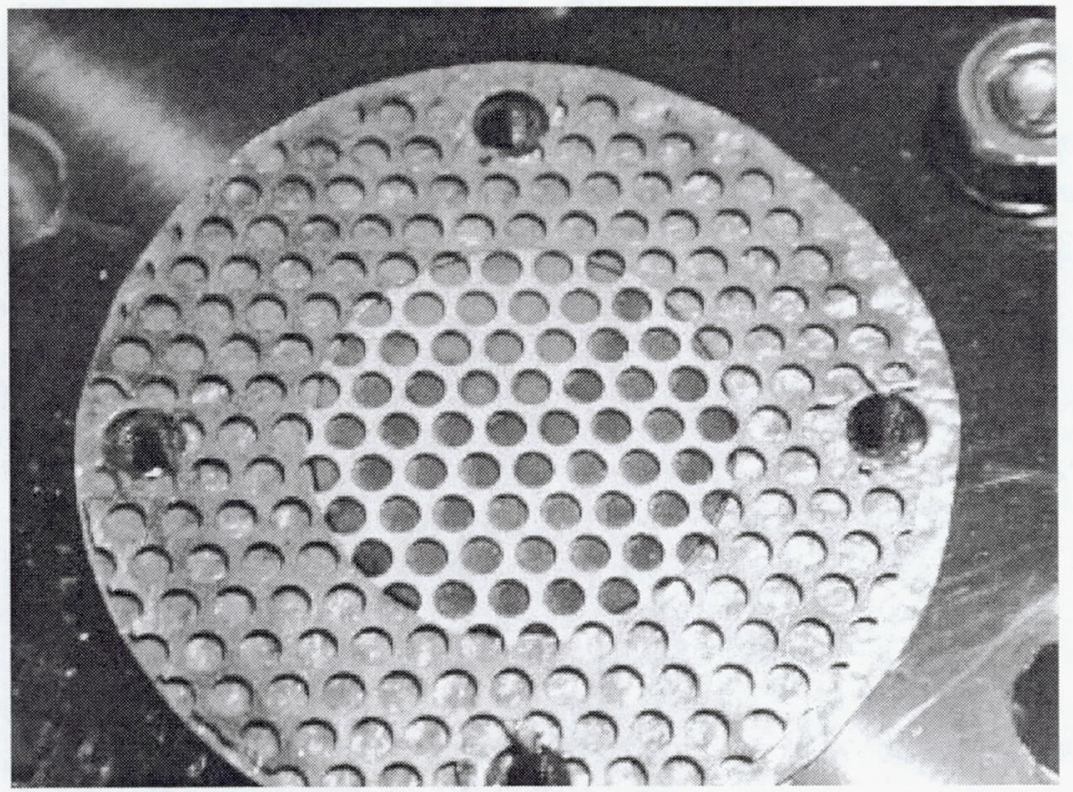

Figure 5. Photo showing an APC-856 PZT ceramic after 5000 shots in unipolar pulse mode. The cathode was operated with a Mo screen on the emitting surface. The ceramic surface is heavily darkened in places. Deposition is evident under magnification; the deposits are most likely sputtered Mo from the emitting surface grids. The presence of deposited material indicates a damaging plasma was produced over the surface of the ceramic.

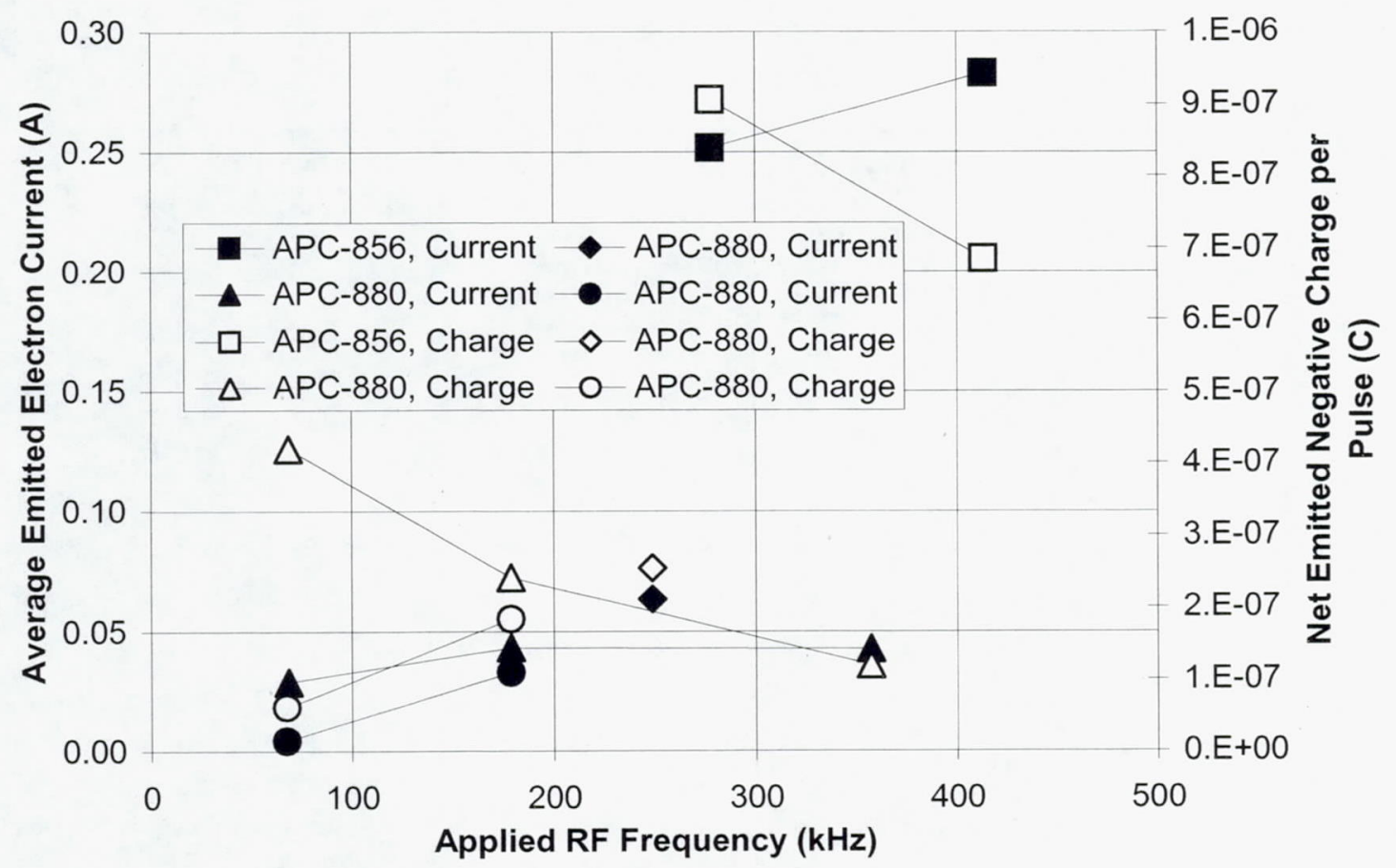

Figure 6. The average electron current (closed symbols) and emitted negative charge (open symbols) from APC-856 and APC-880 PZT ceramic cathodes driven by RF burst are plotted versus RF frequency. The emitted current and charge data were taken at threshold applied voltage. 


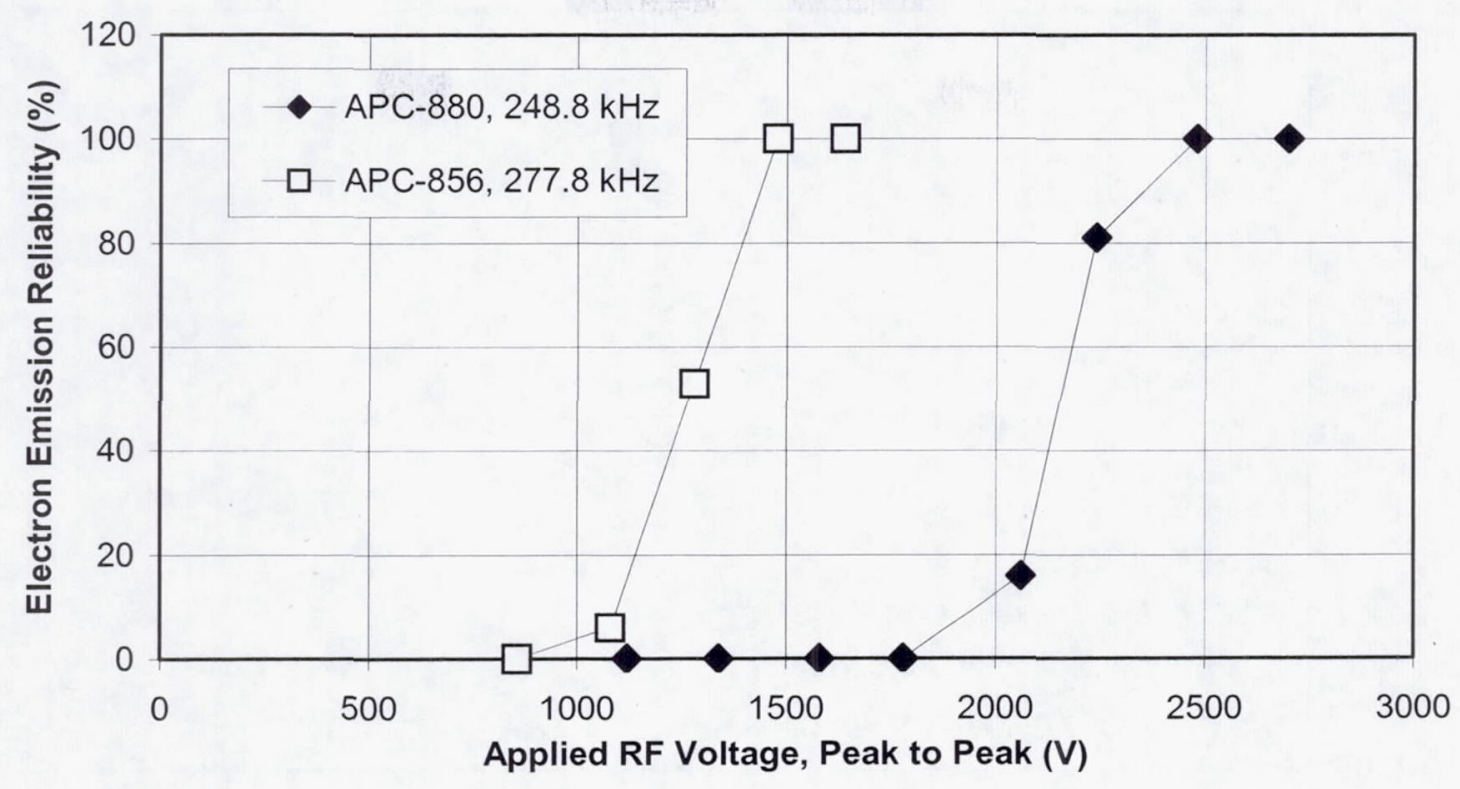

Figure 7. The electron emission reliability as a function of applied voltage is plotted for two PZT ceramics, APC856 and APC-880. Arbitrarily defining the emission threshold as the voltage at which $>80 \%$ of the applied voltage pulses result in electron current measured at the anode, APC-856 has an emission threshold of $\sim 700 \mathrm{~V}$ peak applied voltage and APC-880 has an emission threshold of $\sim 1100 \mathrm{~V}$.

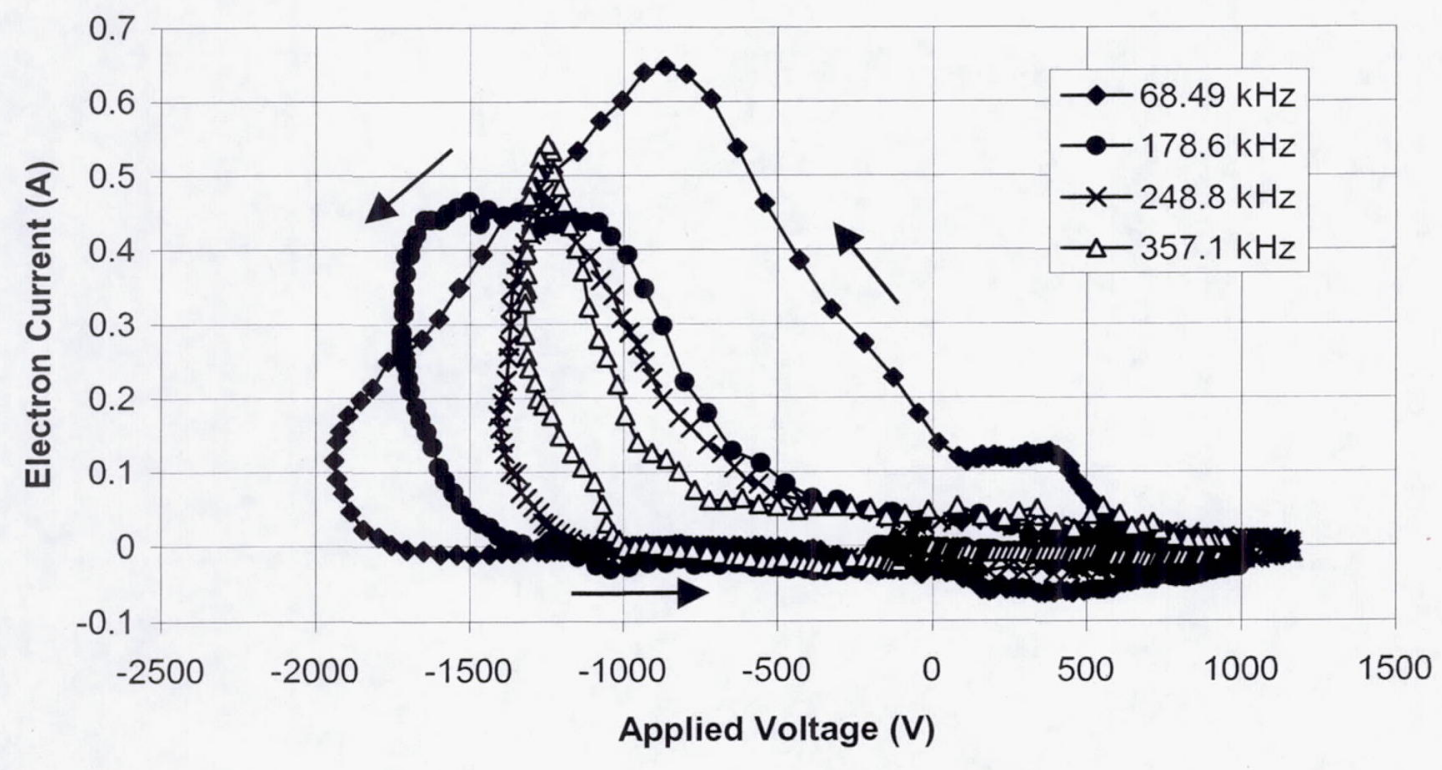

Figure 8. Current-voltage characteristics within an RF cycle are plotted for APC-880 driven at several frequencies. The arrows denote the progression of time through a cycle. Data taken at a driving frequency of $68.49 \mathrm{kHz}$ are an average of 4 cycles; the remaining data are an average of 3 cycles. 


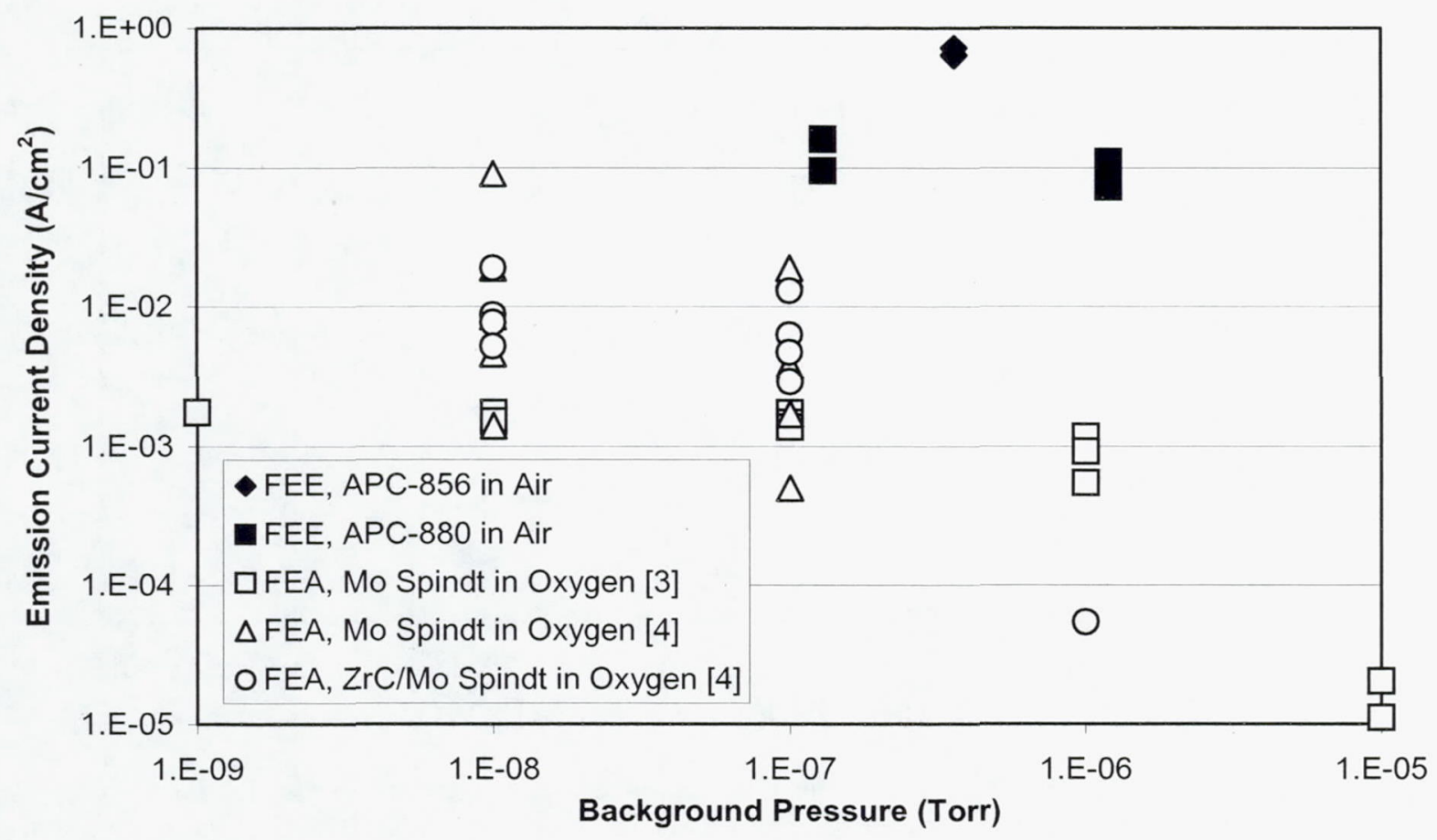

Figure 9. Electron emission current density as a function of background pressure for these ferroelectric cathode experiments and for field emission array cathodes $[3,4]$. The FEE data are from very low duty cycle $\left(10^{-5}\right.$ to $\left.10^{-4}\right)$ RF burst operation over 1000 to 2000 bursts. By contrast, the FEA data were generally taken after an hour or more of DC operation in the gas background. 


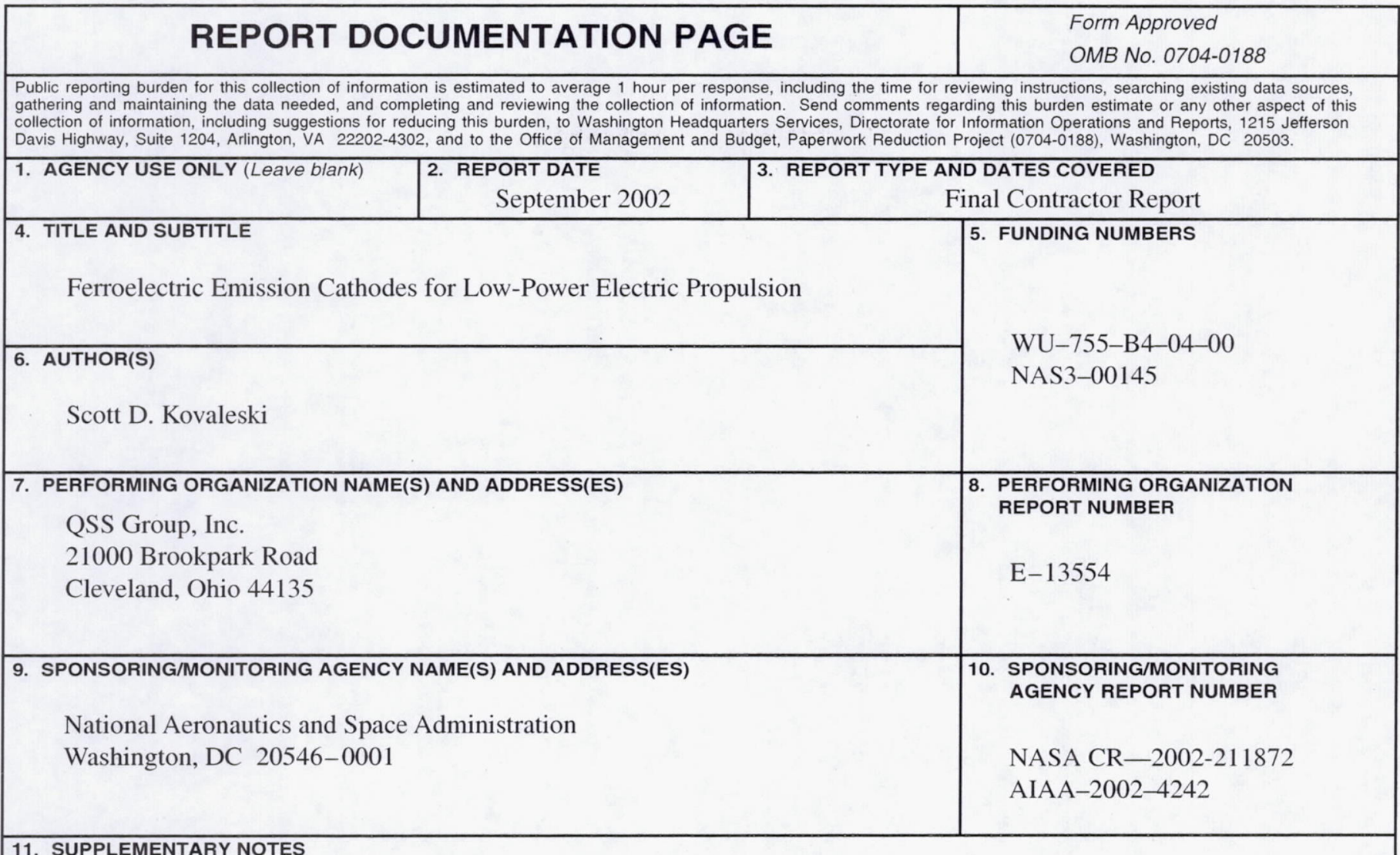

\section{SUPPLEMENTARY NOTES}

Prepared for the 38th Joint Propulsion Conference and Exhibit cosponsored by AIAA, ASME, SAE, and ASEE, Indianapolis, Indiana, July 7-10, 2002. Project Manager, Tom Burke, Systems Engineering Division, NASA Glenn Research Center, organization code 7800, 216-433-5712.

12a. DISTRIBUTION/AVAILABILITY STATEMENT 12b. DISTRIBUTION CODE

Unclassified - Unlimited

Subject Category: 20

Distribution: Nonstandard

Available electronically at http://gltrs.grc.nasa.gov

This publication is available from the NASA Center for AeroSpace Information, 301-621-0390.

13. ABSTRACT (Maximum 200 words)

Low- or no-flow electron emitters are required for low-power electric thrusters, spacecraft plasma contactors, and electrodynamic tether systems to reduce or eliminate the need for propellant/expellant. Expellant-less neutralizers can improve the viability of very low-power colloid thrusters, field emission electric propulsion devices, ion engines, Hall thrusters, and gridded vacuum arc thrusters. The NASA Glenn Research Center (GRC) is evaluating ferroelectric emission (FEE) cathodes as zero expellant flow rate cathode sources for the applications listed above. At GRC, low voltage ( 100 s to $\sim 1500 \mathrm{~V}$ ) operation of FEE cathodes is examined. Initial experiments, with unipolar, bipolar, and RF burst applied voltage, have produced current pulses 250 to $1000 \mathrm{~ns}$ in duration with peak currents of up to $2 \mathrm{~A}$ at voltages at or below $1500 \mathrm{~V}$. In particular, FEE cathodes driven by RF burst voltages from 1400 to $2000 \mathrm{~V}$ peak to peak, at burst frequencies from 70 to $400 \mathrm{kHz}$, emitted average current densities from 0.1 to $0.7 \mathrm{~A} / \mathrm{cm}^{2}$. Pulse repeatability as a function of input voltage has been initially established. Reliable emission has been achieved in air background at pressures as high as $10^{-6}$ Torr.

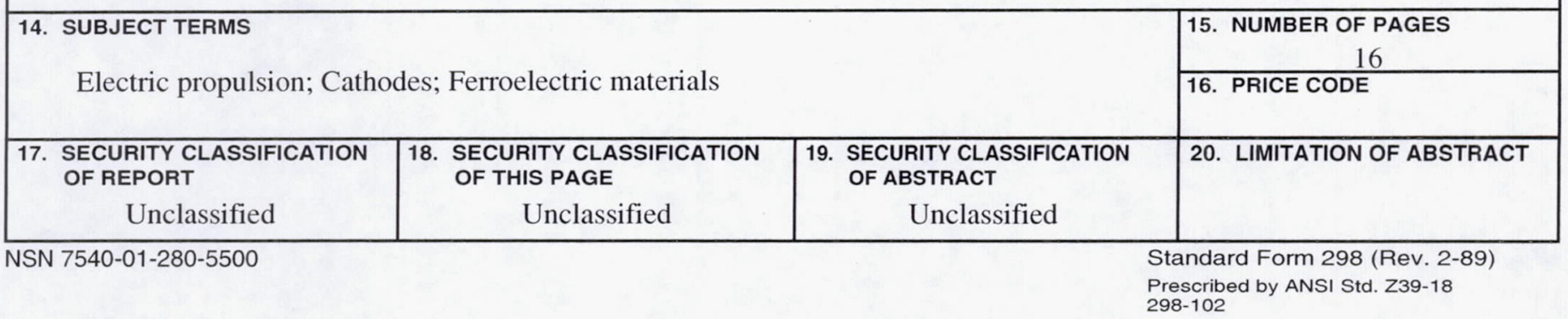

